\title{
Impressions of a touristic route: between the null- dimensional and the three-dimensional
}

\section{SIGRADI2018 TECHNOPOLITICAS \\ xxii congresso da sociedade iberoamericana de gráfica digital 22th conference of the iberoamerican society of digital graphics 07|08|09|novembro|2018 iau usp | são carlos | sp br}

\author{
Adriane Borda Almeida da Silva \\ Universidade Federal de Pelotas | Brazil | adribord@hotmail.com \\ Cristiane dos Santos Nunes \\ Universidade Federal de Pelotas | Brazil | cristiane.nunes@outlook.com \\ Stefani Curth Goulart \\ Universidade Federal de Pelotas | Brazil | stefanigoulart@outlook.com
}

Bethina Harter Silva

Universidade Federal de Pelotas | Brazil | bethinaharters@hotmail.com

\begin{abstract}
This paper reports the experience of a public university digital manufacturing laboratory in producing tactile models to support a tourist route in a historic center. The report includes the reflection on the social and formative, cultural and professional meaning attributed to this production. For this, it uses the theory of the climbing of abstraction, by Vilém Flusser, problematizing the dimensional logic of the media used. This is the representation of the architectural set of the surroundings of a square. Architecture students were involved in the production of the models which were validated by visually impaired individuals.
\end{abstract}

Keywords: Tactile models; Universal design; Digital manufacturing; Architectural heritage; Tourist route.

\section{INTRODUÇÃO}

Um conjunto arquitetônico e paisagístico da cidade de Pelotas-RS foi, recentemente, reconhecido pelo Instituto do Patrimônio Histórico e Artístico Nacional (IPHAN) como Patrimônio Cultural Brasileiro. Incluem-se neste conjunto uma charqueada, uma chácara, um parque e quatro praças, sendo uma destas a Praça Coronel Pedro Osório. Essa se localiza no centro histórico da cidade e possui um entorno que ainda preserva diversos edifícios de arquitetura eclética erguidos entre o final do século XIX e início do XX. Caracterizam-se como um suporte de memória sobre a história da cidade, refletindo a lógica de uma dinâmica social traduzida pela expressão "entre o sal e o açúcar". O referido conjunto de edifícios representa o doce lado desta história, cujo o açúcar era a moeda de troca em um momento em que a mão de obra escrava sustentava a economia da região, com a produção da carne salgada (charque). Com isto a cidade desenvolveu uma cultura de produção de doces que até hoje perdura, inclusive com certificação deste patrimônio cultural. A arquitetura em questão permite reconstruir na memória, quando contraposta à arquitetura que abrigava a indústria saladeril, o propósito de afirmar o poder econômico dos proprietários dos casarões que eram os charqueadores. Estes construíram um cenário urbano, aos moldes europeus da época, que contrapõe totalmente à insalubridade daquele ambiente desumano que configurava o ambiente industrial em questão. Todo este discurso acompanha o roteiro turístico da cidade, que pode ser vivenciado e percebido através da preservação de parte da paisagem urbana, por meio de monumentos, arquiteturas e seus ornamentos.
Especialmente a arquitetura do entorno da Praça Coronel Pedro Osório é rica em elementos que compõem narrativas diversas. Em particular, os estudos de Santos (2007) contribuem para compreender essas narrativas, tratando de analisar o significado de cada ornamento das edificações.

A possibilidade de apropriação destes edifícios como suportes de memória, por qualquer pessoa, está logicamente associada a um conjunto de experiências, envolvendo cada um dos sentidos. Referindo-se à percepção da paisagem urbana, o sentido da visão assume importante papel, sendo necessário proporcionar meios para que pessoas deficientes visuais possam ser incluídas neste processo cultural que exige uma multissensorialidade.

Pereira et al (2017) atenta para o potencial das maquetes físicas de arquitetura, as quais possibilitam ampliar a percepção da forma das edificações e do contexto urbano, para qualquer pessoa, independentemente de suas capacidades visuais. $O$ estudo referido, em particular, traz um aporte científico diferenciado por ter, como autor principal, um profissional experiente em arquitetura, constituindo-se pesquisador doutor em arquitetura após agregar a experiência de perda total do sentido da visão.

Pallasmaa (2011) já enfatizava a importância da própria arquitetura provocar a experiência multissensorial. Tendo-se assim ambas as reflexões trazendo abordagens críticas sobre o ocularcentrismo, referindo-se ao domínio da visão sobre outras modalidades sensoriais na prática de arquitetura. 
Para Pallasmaa "embora as novas tecnologias tenham reforçado a hegemonia da visão, elas também podem ajudar a reequilibrar as esferas dos sentidos" (PALLASMAA, 2011, p.34). Embora esta reflexão esteja direcionada para o contexto da produção de arquitetura propriamente dita, utiliza-se desta ideia também para contextualizar a lógica do uso das tecnologias de fabricação digital.

Tratando-se de um contexto formativo de arquitetura, com um propósito de inclusão dos preceitos do Desenho Universal, nos termos de Ornstein, 2010, os referenciais adotados neste estudo, por um lado, dão suporte para compreender a importância das características multissensoriais da arquitetura e por outro, atentam para a importância dos meios tecnológicos de comunicação para descrever tais características, em especial aquelas que dependem da visão para serem apreendidas.

O emprego das tecnologias de modelagem e fabricação digital por impressão 3D e corte a laser, para o contexto em questão, tem sido guiado pelo propósito de interpretar a atividade de representação como meio de construção de conhecimento, considerando-se que "conhecer é modificar, transformar o objeto, e compreender o resultado dessa transformação" (PIAGET, 1970, p.01). Toda esta interação com o objeto, para ser representado, promove a curiosidade sobre a especificidade formal da arquitetura envolvida, exigindo a compreensão de uma lógica associativa ao contexto histórico, social e cultural do momento em que foi produzida. Com isto, este processo de representação proporciona a construção de narrativas para serem agregadas ao uso dos modelos táteis, reforçando-os como suportes de memória. Uma memória traduzida para uma linguagem universal, atribuindo acessibilidade ao patrimônio arquitetônico em questão.

Dessa forma, o problema abarcado neste trabalho advém do propósito de provocar vivências e afetos, por meio de representações, sobre uma paisagem urbana de interesse patrimonial e arquitetônico. Para a produção destas representações utiliza-se de recursos tecnológicos: fabricação digital de modelos táteis por impressão 3D e corte a laser. Relata-se a experiência de produção de uma maquete física do um conjunto arquitetônico do entorno da Praça anteriormente referida, para apoiar uma rota turística que inclua o público deficiente visual.

O processo de produção da maquete vem sendo realizado por estudantes do Curso de Arquitetura e Urbanismo da Universidade Federal de Pelotas, a partir de uma demanda da Secretaria Municipal de Desenvolvimento e Turismo de Pelotas, de produzir modelos táteis de apoio ao referido roteiro turístico. Este processo está sendo realizado juntamente a pessoas com cegueira e baixa visão através de atividades extensionistas, nas quais os modelos produzidos são avaliados quanto a sua capacidade de comunicação. Ainda se tem a participação de um voluntário cego, que auxilia na escolha das escalas mais adequadas e na simplificação dos modelos para percepção pelo tato. Dessa maneira, trabalha-se na perspectiva de co-design, nos termos de Pereira et al (2017), onde o usuário final do produto atua diretamente no processo de projeto, ao invés de ser representado por um especialista. Esse processo de formação colaborativa vai ao encontro do discurso de Freire (2013), destacando que ações de extensão devem promover a participação ativa dos integrantes do grupo para a construção do conhecimento.

Neste artigo, as representações produzidas são problematizadas utilizando-se da teoria da escalada da abstração de Vilém Flusser (1998). Esta teoria confere dimensões aos meios de comunicação inversamente proporcionais ao grau de abstração exigido para a sua compreensão: parte do tridimensional, referindo-se àqueles que se valem diretamente da experiência com 0 objeto físico, envolvendo o corpo em seus cinco sentidos e por tanto com menor grau de abstração em relação aos demais; avança para o bidimensional, referindo-se ao uso da imagem do objeto, quando produzida por meios tradicionais (desenho); caracteriza o unidimensional, dirigindo-se à escrita (códigos de linguagem); e por fim anuncia o nulodimensional. Esta adimensionalidade corresponde então ao maior grau de abstração, atribuída ao que caracteriza como imagens técnicas, produzidas por aparelhos e passíveis de serem computáveis, de serem transformadas em número. Sob esta lógica dimensional, são observados, então, os recursos representacionais empregados. O processo aqui envolvido transita desde: os objetos arquitetônicos, em concreto, envolvendo todos os sentidos, que compõem a paisagem (tridimensionais); as suas imagens (bidimensionais); aos textos que as descrevem (unidimensionais); às imagens técnicas computacionais, produzidas pelos aparelhos, necessárias para a estruturação da narrativa tátil desta paisagem urbana (nulodimensionais), e por fim, aos modelos físicos em escala adequada ao sentido do tato, os quais podem ser percebidos por todas as pessoas, retornando à tridimensionalidade.

\section{MATERIAIS E MÉTODOS}

A delimitação do método advém de uma trajetória prévia, registrada em Dalla Vecchia et al (2015), de produção e experimentação de modelos também referentes à arquitetura de interesse patrimonial da cidade de Pelotas, porém dirigida à comunicação tátil na escala do detalhe e do edifício, agora aplicada à escala urbana. Para esta nova aplicação, primeiramente, buscou-se entender a infraestrutura pré-existente para a realização do roteiro turístico da Praça Coronel Pedro Osório. Depois, deu-se início à etapa de projeto dos modelos das edificações, para posterior fabricação da maquete tátil. Para o projeto, utilizou-se do método da adição gradual da informação (AGI), como tem sido nomeado neste contexto de estudo, tratando-se de definir, de acordo com a especificidade de cada objeto representado, o número de camadas de informação a serem geradas. Estas camadas referem-se às diferentes escalas de representação para oportunizar a melhor percepção desde o todo da paisagem urbana aos detalhes das edificações. Por fim, buscou-se registrar as reflexões decorrentes de todo o processo frente à teoria da escalada da abstração, avaliando-se a capacidade de comunicação dos modelos produzidos.

\section{INFRAESTRUTURA PRÉ-EXISTENTE}

O turismo tem acompanhado a evolução das tecnologias de informação e comunicação modernizando suas estruturas e qualificando seus agentes para isto. Serviços on-line facilitam aos turistas acessar a informação sobre 
os pontos de interesse em qualquer momento e lugar. Estas possibilidades remetem ao conceito de turismo ubíquo. Conforme Costa (2012), este conceito pode ser compreendido como um guia eletrônico de turismo, que possibilita através de georreferenciamento e de dispositivos móveis, como tablets e smartphones, fornecer informações contextuais de maneira interativa e instantânea do local para o usuário. Certamente, muitos dos roteiros turísticos realizados na Praça Coronel Pedro Osório devem estar sendo dirigidos pela autonomia do turista, sob a consulta em sites especializados, incluindo àquele organizado pela Prefeitura Municipal de Pelotas. Alguns deles avançam também em termos de acessibilidade à informação, disponibilizando recursos de áudio e de tradução para língua de sinais. Além disto, agentes públicos ou privados, promovem passeios acompanhados de um discurso oral, por vezes contando com folders específicos sobre o centro histórico de Pelotas que tem seu ponto focal a referida Praça. Frente a isto, partiu-se desta infraestrutura preexistente, observando-se roteiros já estruturados. Em particular, adotou-se um folder, produzido em 1994 pelo Núcleo de Estudos de Arquitetura Brasileira (NEAB) da Faculdade de Arquitetura e Urbanismo da Universidade Federal de Pelotas. Este material inclui informações textuais e ilustradas, dirigidas, especificamente, ao ambiente urbano de interesse neste trabalho, fruto de projetos de investigação. Com partes ilustradas pela Figura 1, 0 material referido contém textos relativos à história da Praça Coronel Pedro Osório e de seu entorno. A numeração localiza, sobre um mapa, as edificações de interesse patrimonial remetendo aos dados históricos e características arquitetônicas principais de cada uma delas, como exemplificado, na mesma imagem, pelo caso da sede da Prefeitura Municipal de Pelotas.

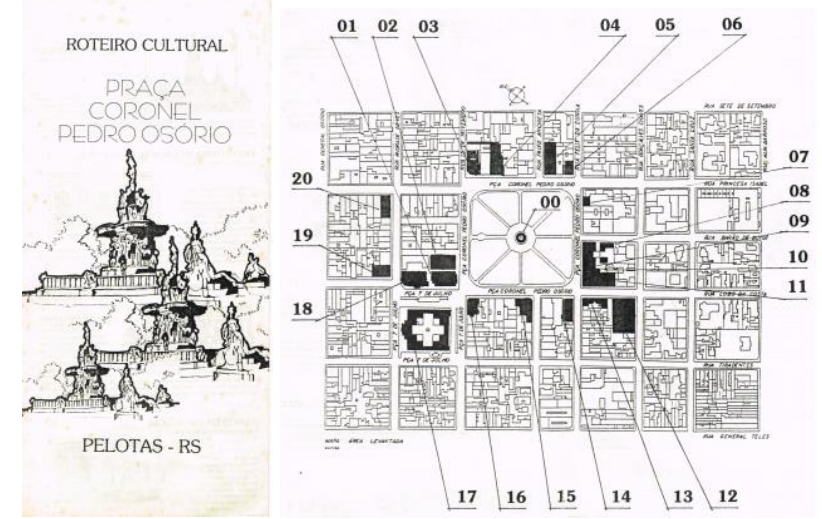

PREFEITURA MUNICIPAL DE PELOTAS

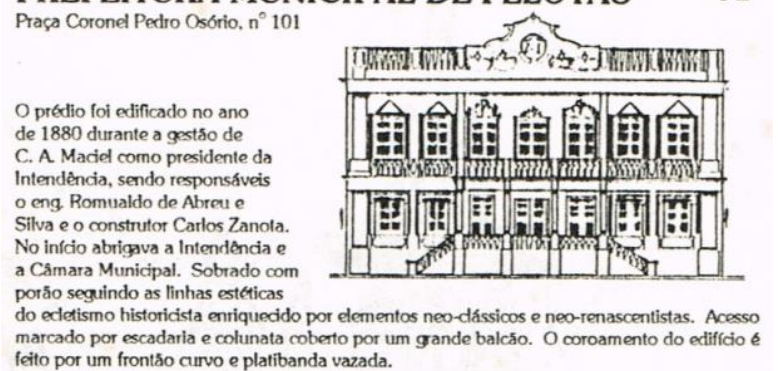

Figura 1: llustrações do folder sobre a Praça Coronel Pedro Osório. A) Capa do folder. B) Mapa do entorno da praça, destacando-se os edifícios ecléticos. C) Exemplo de descrição realizada sobre os edifícios. Fonte: Núcleo de Estudos de Arauitetura Brasileira - FAUrb/UFPel.

\section{MODELAGEM DIGITAL DOS EDIFÍCIOS}

Os modelos digitais de todo o entorno urbano foram executados a partir das seguintes fontes: documentação arquitetônica disponibilizada pelo NEAB/FAUrb/UFPel e pela Prefeitura Municipal de Pelotas (PMP); imagens obtidas no Google Maps (https://www.google.com.br/maps/), através da ferramenta Street View; imagem em alta resolução da área, disponibilizada pela PMP; mapa vetorizado do lugar com a marcação dos lotes; modelos digitais disponíveis no Armazém 3D (https://3dwarehouse.sketchup.com), relativos à produção do Projeto MODELA Pelotas (GEGRADI/FAUrb/UFPel), conforme consta no registro junto a esta plataforma de modelos. Contou-se também com dados obtidos por meio de tecnologias de fotogrametria digital e escaneamento 3D a laser, para o caso de uma das edificações. Desta maneira, as fontes de dados foram diversas, sempre que possível sobrepondo-se informações para avançar em termos de precisão para a representação. Entretanto, este aspecto (precisão de medidas) não chega a adquirir relevância frente às escalas de representação, aos objetivos e às tecnologias empregadas. Conforme Pereira et al (2017), modelos táteis precisam ter formas simples, ampliando-se detalhes relevantes e eliminando-se aqueles que produzem ruídos à percepção tátil. Desta maneira, mesmo partindo-se de representações digitais que já haviam sido executadas, mas para serem visualizadas no espaço digital, foi necessária uma remodelagem visando tal simplificação/ampliação de detalhes, específicos para cada caso e próprios para cada escala.

A sequência de imagens da Figura 2 exemplifica um processo de simplificação de fachada. A primeira referese a uma fotografia retificada, neste caso da fachada principal do Casarão da Família Assumpção, edificado em 1887. Esta fotografia foi utilizada como textura para um modelo digital para ser visualizado na plataforma Google Earth em 3D. Desta maneira, tem-se uma representação fotorrealista, informando apenas visualmente a complexidade formal, sem contudo corresponder com a geometria espacial da ornamentação da fachada. A segunda imagem, refere-se a mesma fachada, de um modelo produzido no âmbito deste estudo, para ser impresso na escala 1:75, portanto sem textura, mas já incluindo, de maneira simplificada, a geometria dos ornamentos. Esta simplificação decorreu das orientações dos colaboradores com deficiência visual, controlando o grau de rugosidade possível para perceber cada elemento individualmente pela ponta dos dedos. A terceira imagem traz a mesma fachada ainda mais simplificada, por se tratar do modelo para a impressão na escala da maquete da Praça (1:500), compatibilizando, de certa maneira, os limites da tecnologia empregada. O propósito, neste caso, está em informar tipologias das edificações e proporções entre elas, para a percepção da configuração de todo o entorno em questão.
3 


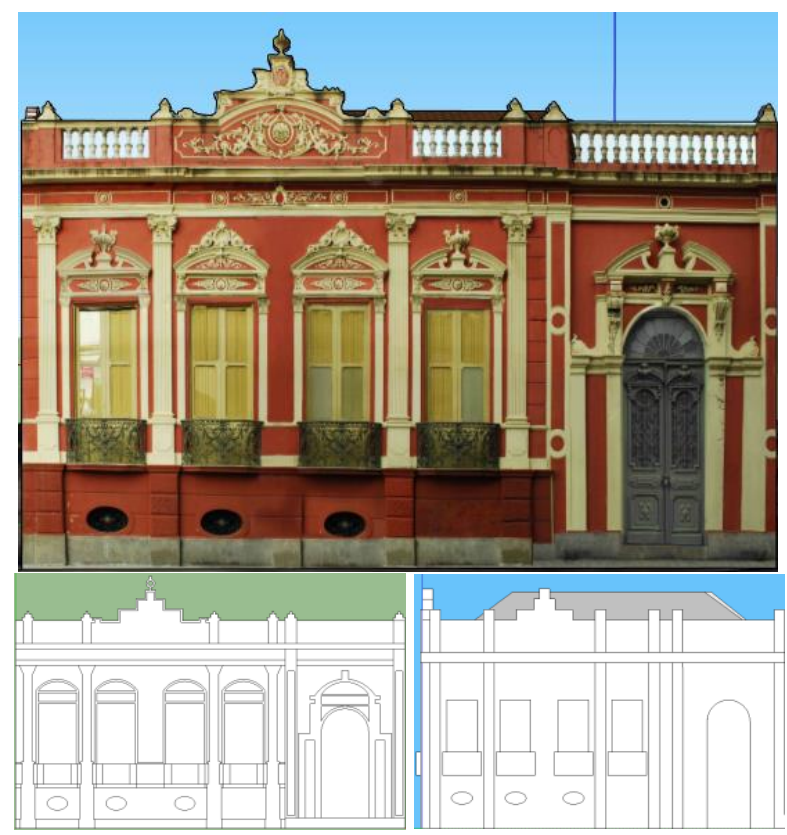

Figura 2: Simplificações realizadas no Casarão da Família Assumpção. A) Imagem do modelo disponível no Armazém 3D. B) Modelo simplificado para a escala 1:75. C) Modelo simplificado para a escala 1:500. Fonte: Autoras, 2017.

O critério para a simplificação da geometria das fachadas foi conduzido essencialmente pelos textos relativos às características arquitetônicas que particularizam cada edificação, constantes no folder de referência. Para o caso do Casarão relativo às fachadas da Figura 2, por exemplo, a descrição textual ressalta o tipo de edificação e a situação em relação ao quarteirão: "casarão de esquina e de partido de corredor lateral" (situado no canto superior esquerdo da Figura 3, parecendo a letra $\mathrm{E}$ refletida). O texto enfatiza a presença de um porão alto, habitável e com aberturas em formato elíptico, denominadas gateiras. Destaca também a existência de pilastras, marcando o ritmo da fachada. Foi necessário ainda representar outras volumetrias para ilustrar a seguinte descrição: "...corpo com vãos de sacada de púlpito em ferro, esquadrias com bandeira de verga reta e com ornamentos, de massa, na parte superior...". Observa-se que todo este detalhamento, incluindo o dos elementos que sustentam o coroamento da fachada, aparecem particularizados na escala de 1:75. Nesta escala promove-se a tradução tátil do seguinte texto "...cimalha com cornija, friso e arquitrave profusamente trabalhada", elementos que na escala de 1:500 fundemse em uma única saliência.

Toda a narrativa tátil está programada para partir da escala 1:500, tendo-se a maquete da paisagem urbana (localização, orientação, forma e proporção) como dispositivo inicial. Logo, devem ser particularizadas as edificações, avançando-se na descrição dos detalhes.

A partir da Figura 3, observa-se o propósito de diferenciar os edifícios por meio do uso de diferentes materiais e tecnologias de fabricação: os inventariados ou tombados, relativos à arquitetura eclética, estão sendo produzidos em PLA (polímero poliácido láctico) branco, a partir da tecnologia de impressão 3D (método aditivo, por deposição de camadas de PLA fundido). O acabamento opaco permite a compreensão da forma por pessoas com baixa visão; as demais edificações estão sendo produzidas em MDF (placa de fibra de média densidade), a partir do corte a laser. Até o momento estas representações referem-se apenas ao sólido envolvente das edificações, sem adicionar nenhum detalhe de fachada. Os modelos digitais foram produzidos a partir da extrusão dos polígonos dos lotes de um mapa vetorizado, disponibilizado pela PMP, respeitando-se as respectivas alturas das edificações.

A base da maquete está constituída por uma imagem aérea, em alta resolução, da Praça e de seu entorno. Desta maneira, busca-se facilitar também a compreensão de pessoas sem deficiência visual. O contraste de materiais também facilita a identificação e diferenciação dos edifícios históricos por pessoas com baixa visão.

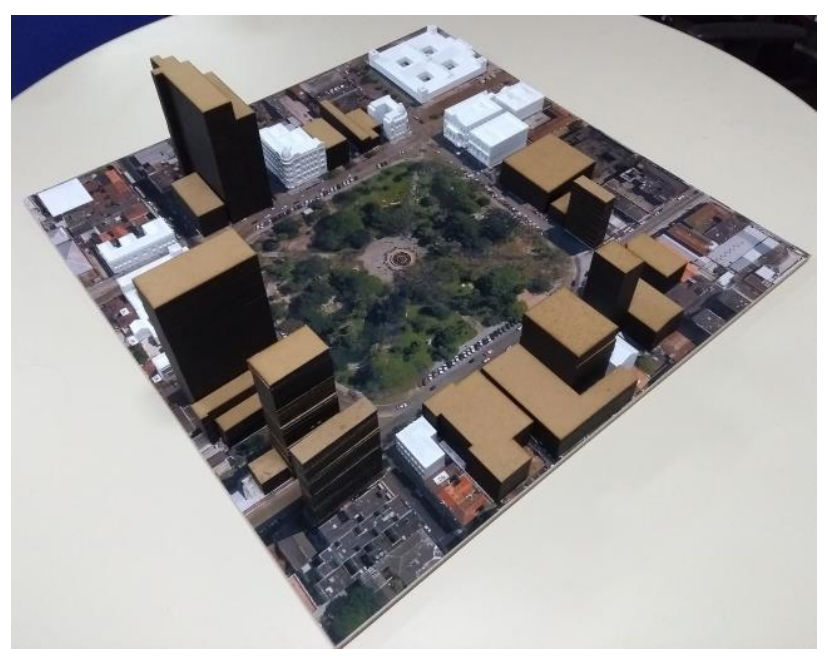

Figura 3: Fotografia da maquete tátil. Fonte: Autoras, 2018.

\section{APLICAÇÃO DO MÉTODO AGI}

O método AGI, para a maior parte das edificações, até o momento, foi aplicado em apenas duas escalas. Em sintonia com Pereira et al (2017), buscou-se inicialmente ter a volumetria geral da edificação (1:500) e logo ter modelos parciais das mesmas contemplando fachadas principais na escala 1:75, como ilustrado na Figura 4. A lógica, de particularização destas fachadas, é de provocar a percepção sobre as diferenças de linguagem das composições arquitetônicas, destacando as identidades de cada edifício. De acordo com o propósito do discurso que acompanha a ação cultural tem-se o método aplicado em maior número de escalas. A representação do edifício do Grande Hotel, obra concluída em 1928, foi descrito em Dalla Vecchia et al (2015), utilizando-se de cinco camadas de representação, variando de 1:500 à 1:10, especificamente para descrever a cúpula desta edificação, ilustrada na primeira imagem da Figura 4.

\section{AVALIAÇÃO DOS MODELOS PRODUZIDOS}

A avaliação da qualidade dos modelos para a experiência tátil está sendo acompanhada por um estudante de Museologia, atualmente com limitação total do sentido de visão, porém com memória visual recente, inclusive tendo um repertório necessário para o reconhecimento da arquitetura representada. Conta-se também com o uso dos modelos por estudantes da Escola Louis Braille, abarcando uma grande diversidade em termos de grau de deficiência, idade, gênero, nível de escolaridade e 
cognitivo, envolvendo um mínimo de vinte pessoas. As imagens da Figura 4 ilustram um destes momentos de experimentação, em junho de 2018 junto a uma turma de adultos da Escola citada. Percebe-se a flexibilidade do recurso em permitir destacar cada um dos modelos para serem totalmente manuseados e associados aos modelos que complementam a informação dos mesmos em outra escala, referentes a partes destes edifícios (segunda imagem). A cada momento de uso são registradas, por fotografia e por vídeo, as percepções tanto por parte da equipe envolvida como por parte dos usuários. Desta maneira, busca-se captar toda a informação para compreender como os recursos disponibilizados acionam um processo de educação patrimonial. Mesmo sem ainda ter havido uma análise sistematizada dos registros fotográficos e de vídeo, estes evidenciam a expressão de afetos de todos os envolvidos e o uso efetivo dos modelos como suportes de memória. Dentre estas evidências foi possível registrar a produção de uma criança com deficiência visual, do grupo da Escola, realizada de maneira espontânea, em um momento imediatamente após a experiência com a maquete. Ela tentou reproduzir, utilizando-se de peças de montar, o modelo experenciado.

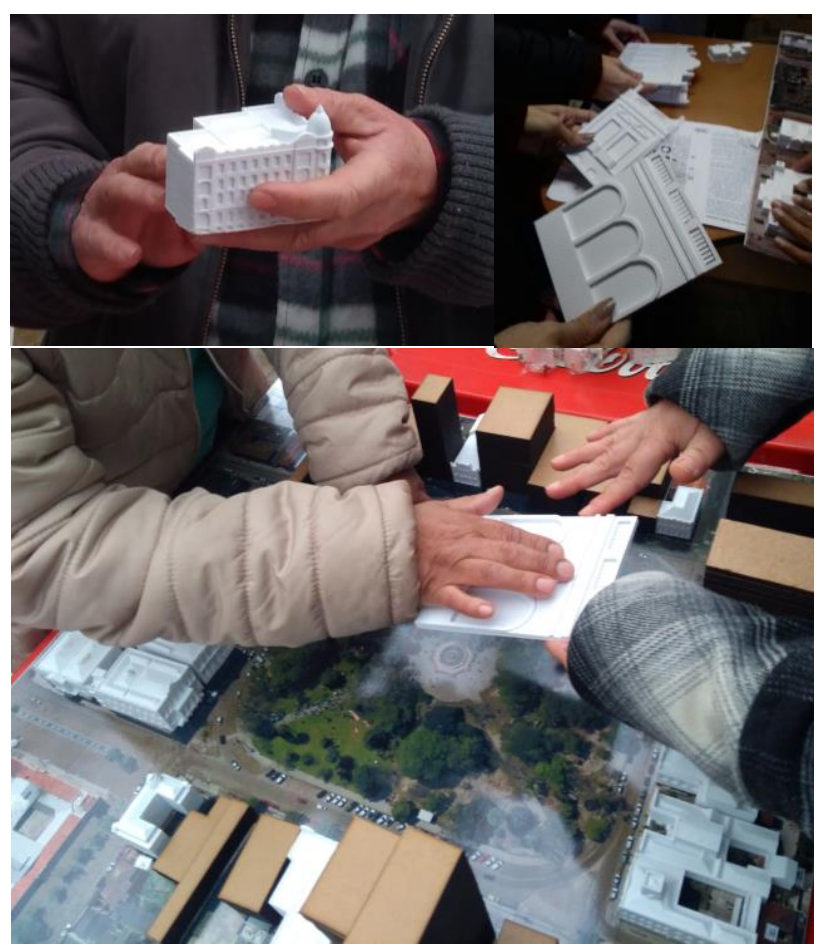

Figura 4: Registro fotográfico do uso da maquete junto a uma ação realizada na Escola Louis Braille de Pelotas em junho/2018. Fonte: Autoras, 2018.

Frente a isto, até o momento, tem-se uma avaliação de caráter qualitativo, evidenciando-se o potencial das representações para intensificar a interação entre universidade e sociedade.

Tais dispositivos seguem sendo incrementados para representar, pelo método AGI, todos os edifícios destacados no folder de referência. Até agora foram representados doze dos vinte ali referenciados. Além disto, existe o propósito de evidenciar também a linguagem arquitetônica dos demais edifícios do entorno (não inventariados ou patrimoniados). Em um primeiro momento, utilizando-se da adição de texturas por meio de ortofotos destes edifícios. Em um segundo momento, aplicando-se também o método AGI, facilitando a leitura de toda a paisagem urbana em questão.

\section{RESULTADOS E DISCUSSÕES}

Os resultados esperados para este estudo referem-se à reflexão sobre como todo o processo de produção dos modelos táteis está contribuindo para a contextualização e compreensão sobre o significado do emprego das tecnologias de fabricação digital. A teoria da escalada da abstração de Vilém Flusser (1998) é adotada para problematizar este processo. Observa-se para isto a lógica dimensional dos recursos representacionais empregados e como tal ação pode elucidar a reflexão proposta. O processo envolvido refere-se ao ato de representar, nos termos piagetianos, de construção de conhecimento. Dada a escala do objeto (paisagem urbana) a interação se refere inicialmente à vivência do espaço, no tridimensional, proposta a ser intensificada por um roteiro turístico com o apoio de uma maquete de caráter assistivo. Desta maneira, há o envolvimento de todos os sentidos, incluindo a proposta de complementação da informação para as pessoas deficientes visuais, tratando de um nível de abstração menor possível em termos comunicacionais em relação à forma desta paisagem. Embora ainda não tenha havido uma análise sistematizada para compreender a eficiência do recurso, já se teve um indício, conforme comentado anteriormente, com a abstração de uma criança na tentativa de reproduzir o modelo tátil. Quanto à produção de representações bidimensionais, nos termos flusserianos (pelo desenho), identifica-se o exercício dos estudantes de arquitetura, ao vetorizarem os elementos que compõem as fachadas dos edifícios, desta maneira, transitando pela bidimensionalidade no processo abstracional/interacional que envolve uma maior atenção sobre a forma e seu significado no âmbito das linguagens de arquitetura envolvidas. O exercício de reconhecer e traduzir as representações unidimensionais (descrições textuais das edificações), por parte da equipe de mediação exige a apropriação efetiva do discurso sobre o objeto representado como um todo (paisagem urbana). Os depoimentos orais dos usuários têm demonstrado também tal apropriação, embora não tenha sido oportunizada a expressão escrita, a qual terá que envolver o sistema estruturado pelo pedagogo francês Louis Braille (1809-1852), sistema tátil formado por pequenos pontos salientes para serem decifrados pela ponta dos dedos. Destaca-se que a Escola Louis Braille, envolvida nas ações, já se disponibilizou a adicionar este sistema de escrita ao recurso. A associação do discurso ao modelo tem se constituído como uma ação lúdica de perceber tatilmente a narrativa traduzida em forma arquitetônica. Por fim, compreende-se o uso da fotografia, da fotogrametria digital, do escaneamento 3D a laser, da representação digital por modelagem e da produção por fabricação digital, todas em princípio, interpretadas no âmbito das imagens técnicas, computáveis, envolvendo um alto nível de abstração. Para o contexto acadêmico, por meio da trajetória de aprendizado proposta, cada uma delas está guiada por uma consciente intenção de uso e controle de um tipo específico de produção. Desta maneira, não se trata de uma prática representacional que atribui autonomia ao aparelho. Ao contrário, foge da postura "proletária" 
associada ao tipo de relação a ser evitada, do usuário com tais tecnologias, alertada por Flusser.

As informações contidas no folder de referência, bi e unidimensionais (desenhos e textos) foram assim ampliadas, partindo e retornando à tridimensionalidade, utilizando-se da trajetória de uso das imagens técnicas, nulodimensionais.

Adiciona-se ainda uma reflexão sobre o possível incremento à infraestrutura de um turismo ubíquo. Referese à perspectiva, com a popularização das práticas de impressão 3D e a disponibilização dos arquivos digitais de maneira aberta, de acesso aos modelos táteis em qualquer lugar. Isto poderá contrapor à problemática de tempo necessário para experenciar as diferentes camadas de informação para a compreensão de um edifício ou espaço urbano. Deve-se ter em conta que uma pessoa deficiente visual necessita de mais tempo para adquirir informação suficiente, por meio do tato, capaz de contribuir para a construção da imagem mental.

\section{CONSIDERAÇÕES FINAIS}

O processo de representação aqui referido, por um lado, constitui-se como infraestrutura para promover a inclusão cultural de pessoas deficientes visuais. Por outro, como oportunidade para promover uma formação profissional em arquitetura, sensível e apta ao Desenho Universal e à interação com a sociedade, tendo em vista a experiência de caráter extensionista.

O exercício de realizar uma leitura dos meios de comunicação envolvidos em todo o processo, apoiado nas reflexões flusserianas tem induzido ao estabelecimento de um ambiente acadêmico reflexivo especialmente quanto à postura de uso das tecnologias digitais de representação. E, mais do que isto, desloca o objetivo didático centrado no tempo tecnológico atual para a construção de uma postura atenta a qualquer tempo.

Partiu-se de um resultado concreto, o "maquetão", como tem sido tratado no contexto do estudo, avançando-se para resultados essencialmente qualitativos. Estes expressados pelo afeto das pessoas que vivenciam a experiência, tanto por parte dos usuários dos modelos e da equipe de desenvolvimento das representações. Tal experiência, a todo momento transita pelos diferentes níveis de abstração. As representações, produzidas por fabricação digital, estão carregadas de significado: social, formativo, cultural e profissional. Podem ser reproduzidas em série, pelos aparelhos, entretanto, são os momentos de interação com estas representações que possibilitam a transgressão ou a criatividade para avançar com a inclusão cultural e com o aperfeiçoamento do processo formativo para o projeto. Desta interação é possível que surjam outras representações ainda impensadas, avançando em todo processo comunicacional.

\section{AGRADECIMENTOS}

À equipe do NEAB/UFPel, por facilitar o acesso às informações sobre o patrimônio arquitetônico pelotense representado. À Escola Louis Braille e ao colaborador, Lheandro Freitas Pereira, estudante de Museologia da UFPel, deficiente visual.

Ao engenheiro Diego Sacco Silveira, que desenvolveu o trabalho de escaneamento 3D e apoiou todo o processo formativo dos bolsistas para o tratamento de nuvem de pontos e configuração dos modelos para a impressão 3D.

À Rafael Eslabão, pela incansável parceria e investimento na ciência, que fez garantir a resolução dos problemas com as tecnologias de fabricação digital.

À equipe de professores, funcionários e bolsistas do GEGRADI (Grupo de Estudos para o ensino/aprendizagem de Gráfica Digital), FAUrb/UFPel, que apoiou o desenvolvimento de todo o estudo.

\section{REFERÊNCIAS}

COSTA, Cristiano. UbiTour: Um Guia Eletrônico de Turismo Ubíquo para Dispositivos Móveis. Disponível em: http://www.cristianocosta.com.br/pesquisa/ projetos-depesquisa/ (acesso em 11/07/2012).

DALLA VECCHIA, Luisa; DA SILVA, Adriane; PIRES, Janice; VEIGA, Monica; VASCONSELOS, Tássia; BORGES, Letícia. (2015). Tactile models of elements of architectural heritage: from the building scale to the detail. In: 16th CAAD Futures Conference, 2015, São Paulo. The next city - New technologies and the future of the built environment. p. 434446.

FLUSSER, V. Ensaio sobre a Fotografia. Para uma filosofia da técnica. (Apresentação de Arlindo Machado). Lisboa: Relógio d'Água, 1998.

FREIRE, Paulo. Extensão ou comunicação? Rio de Janeiro: Paz e Terra, 2013.

ORNSTEIN, S.W. (org.).(2010). Desenho universal: caminhos da acessibilidade no Brasil. São Paulo: Annablume.

PALLASMAA, Juhani. (2011). Os olhos da pele: a arquitetura e os sentidos. Porto Alegre: Bookman.

PEREIRA, Carlos Mourão. HEITOR, Teresa Valsassina. HEYLIGHEN, Ann. (2017). Exploring invisibility through multisensory spatial research methods. Quality and Reflexivity in Qualitative Inquiry. European Congress of Qualitative Inquiry Proceedings 2017; 2017; pp. 9 - 18.

PIAGET, J. (1970). Epistemologia Genética. São Paulo: Martins Fontes, 2002.

SANTOS, Carlos Alberto Ávila. Ecletismo na fronteira meridional do Brasil: 1870-1931. Tese (Doutorado em Arquitetura e Urbanismo - Área de Conservação e Restauro) Universidade Federal da Bahia, 2007. 